\title{
Risk stratification in differentiated thyroid cancer with RAI-avid lung metastases
}

\author{
Keiko Ohkuwa, Kiminori Sugino, Mitsuji Nagahama, Wataru Kitagawa, Kenichi Matsuzu, Akifumi Suzuki, \\ Chisato Tomoda, Kiyomi Hames, Junko Akaishi, Chie Masaki and Koichi Ito
}

Department of Surgery, Ito Hospital, Tokyo, Japan

Correspondence should be addressed to K Ohkuwa: k-ohkuwa@ito-hospital.jp

\begin{abstract}
Objective: Radioactive iodine (RAI) therapy is effective for differentiated thyroid cancer (DTC) patients with lung metastasis. However, some patients have a poor prognosis despite the RAI accumulation. The utility of inflammatory biomarkers, including neutrophil-to-lymphocyte ratio (NLR), has been reported as a prognostic factor for many carcinomas. This study aimed to investigate the risk factors related to DTC patient survival with RAl-avid lung metastasis and to attempt risk stratification.

Design and methods: This retrospective study included 123 patients with RAI-

accumulating lung metastatic DTC. The cause-specific survival (CSS) rate from the time of detection of lung metastasis was tested using the Kaplan-Meier log-rank test, and the multivariate analysis was calculated using the Cox proportional hazards model. NLR was retrospectively calculated using the blood sample collected before initial RAl treatment. The NLR cutoff value was 2.6 on the ROC curve.

Results: Age $\geq 55$ years at the time of operative treatment, follicular carcinoma, lung metastasis tumor $\geq 10 \mathrm{~mm}$ in diameter, age $\geq 55$ years at the time of detection of lung metastasis, age $\geq 55$ years at the time of RAI treatment, and NLR $\geq 2.6$ at the initial RAI treatment were predictive of decreased CSS. Multivariate analysis identified that the independent prognostic factors were lung metastatic tumor $\geq 10 \mathrm{~mm}$ in diameter and $N L R \geq 2$.6. Patients in the high-risk group with both factors had significantly lower CSS rates than those in the low- and intermediate-risk groups with one or none of these factors.

Conclusions: The high-risk group patients had significantly poorer survival, and these patients could be considered as future candidates for tyrosine kinase inhibitor therapy.
\end{abstract}

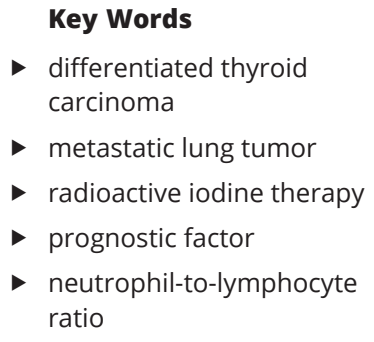

Endocrine Connections (2021) 10, 825-833

\section{Introduction}

The incidence of thyroid cancer has increased over the previous decade. The 5- and 10-year relative survival rates for patients with differentiated thyroid cancer (DTC) are $90-95 \%(1,2)$. Distant metastasis occurs in $5-20 \%$ of patients with DTC and is predominantly observed in the lungs and bone $(3,4,5,6)$. When treating metastatic tumors of differentiated thyroid carcinoma, a favorable prognosis can be expected after radioactive iodine (RAI) therapy after total thyroidectomy (7). Therefore, RAI therapy is effective for patients with DTC with metastasis; only two-thirds of distant metastases have been reported to show substantial RAI uptake, and only approximately $42 \%$ of cases are cured (8). Moreover, RAI therapy is ineffective in approximately $30 \%$ of cases of DTC with distant metastasis $(8,9)$.

In recent years, cases in which disease progresses after RAI therapy or accumulation does not occur are considered cases of RAI-refractory differentiated thyroid cancer (RAIR-DTC), for which treatment with tyrosine kinase

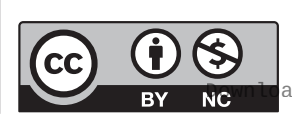

This work is licensed under a Creative Commons Attribution-NonCommercial 4.0 International License. ded from Bioscientifica.com at 04/26/2023 06:09:23AM 
inhibitors (TKI) is to be considered. The 10-year survival rate of patients undergoing RAIR-DTC is reported to be $<10 \%$ and the prognosis is poor $(8,10)$. The criteria to determine RAIR are as follows: (i) no accumulation of RAI, (ii) tumor growth even with little accumulation of RAI, and (iii) tumor growth after RAI therapy ( $\geq 600 \mathrm{mCi}$ ). Based on the American Thyroid Association Guidelines, 18F-fluorodeoxyglucose PET/CT (18FDG-PET/CT), wholebody scan (WBS), CT, and serum thyroglobulin (Tg) are recommended in combination for identifying RAIR-DTC (7), but none of these tests are simple or convenient. In principle, patients with metastatic disease showing RAI accumulation should continue with RAI therapy, but whether it is refractory needs to be determined after several RAI treatments, and no studies have yet suggested any clinical features to help make a decision in the early stages of RAI therapy. Some recent reports indicate the efficacy of improving prognosis via TKI treatment in RAIR cases $(10,11)$. Ideally, in the case of continued RAI therapy, the likelihood of resistance to RAI therapy should be determined at the appropriate time, and more time should be spent on effective treatments, including TKI administration. Hence, searching for predictable biomarkers that may contribute to the selection of appropriate treatment methods is necessary.

Systemic inflammatory biological reaction is associated with cancer cell proliferation and worsened prognosis. Neutrophil-to-lymphocyte ratio (NLR), one of the indicators of inflammation and immunology, is easily measured via peripheral blood sampling and is reportedly useful as a prognosis index of various types of cancer (12, $13,14,15)$. Several studies have investigated the role of NLR in thyroid cancer, and reports evaluating changes in inflammatory markers and blood-cell count due to RAI treatment exist, but no reports of studies on the correlation between NLR and prognosis in patients with RAI-avid lung metastasis were found $(16,17)$. This study aimed to determine the clinical prognostic factors, including NLR, in RAI-avid lung metastasis cases and to attempt risk classification to identify future cases for TKI therapy.

\section{Patients and methods}

This was a retrospective study of patients diagnosed with DTC at our hospital. RAI treatment was performed in 481 patients with distant metastasis of DTC at Ito Hospital from January 2000 to December 2018. A total of 387 (80.5\%) patients showed metastatic lung tumors at the first time of metastatic lesion diagnosis, of which 129 (33.3\%) displayed
RAI accumulation at the time of first RAI treatment. Of the 129 patients who showed accumulation in the lungs, six patients were excluded from the study because they only underwent a WBS with a small amount of iodine to confirm accumulation, and a therapeutic dose was not administered. Among the patients of DTC with lung metastasis treated using RAI, we retrospectively reviewed 123 cases with accumulation in metastatic lesions (Fig. 1). The only organ that demonstrated metastasis at the time of the first RAI treatment was the lung. Furthermore, nine cases of bone metastasis and three cases of multi-organ metastasis were observed during follow-up. No cases with infection or inflammatory disease were noted at the time of metastatic lesion diagnosis. Lung metastasis was confirmed by any of the following methods: (i) lung metastatic lesion pathologically confirmed by biopsy specimen, (ii) localized or diffused uptake into the lungs confirmed by WBS, and (iii) metastasis indicated by diagnostic imaging, such as chest CT. Metastases diagnosed within 6 months after initial operative treatment were considered as synchronistic lung metastases cases.

All patients in this study underwent total thyroidectomy. Prophylactic central lymph node dissection was routinely performed when the patients underwent thyroidectomy. Lateral lymph node dissection was performed in the presence of CT, ultrasound, or clinically evident lymph node involvement using a compartment-based approach. RAI dose per treatment was 3.7 $\mathrm{GBq}(100 \mathrm{mCi})$. A post-therapy WBS was performed 2 days after iodine-131 administration. RAI accumulation

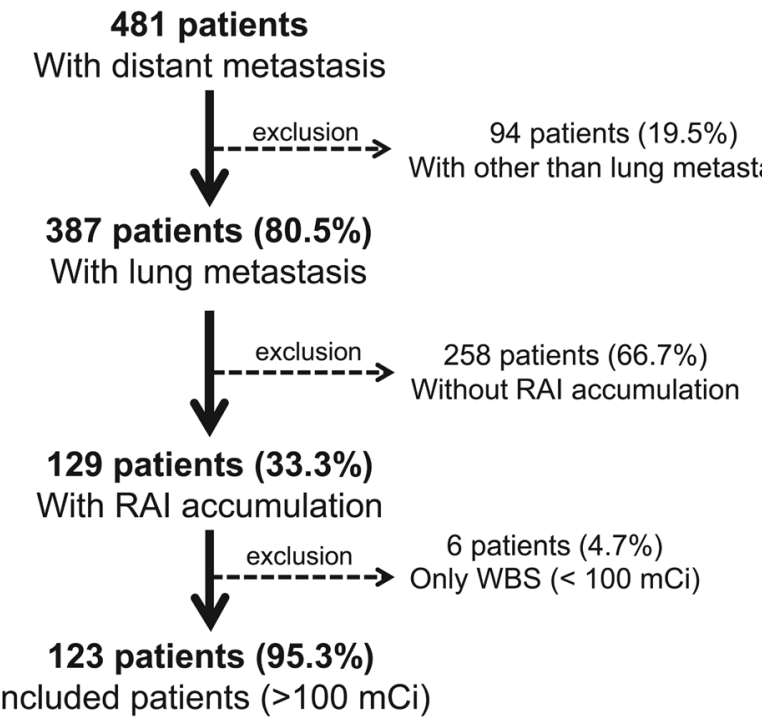

Figure 1

Selection of patients included in the analysis. 
was determined using whole-body scintigraphy. Treatment was performed approximately every year while monitoring the intensity of RAI accumulation, Tg (thyroglobulin) levels under TSH stimulation, and the status of lung masses using CT. Peripheral blood was collected on the day of initial RAI treatment. Lung metastases were evaluated using CT. After treatment, TSH suppression therapy was performed via oral administration of levothyroxine sodium with target serum TSH of $<0.1 \mu \mathrm{IU} / \mathrm{mL}$.

The endpoint of this study was cause-specific survival rate (CSS), and the evaluation items were age at initial operation, sex, histopathology, time of lung metastasis detection, and maximum tumor diameter at the time of lung metastasis detection, age at initial RAI treatment, and NLR at time of initial RAI treatment. NLR was calculated by dividing the peripheral blood neutrophil count immediately before the first RAI treatment by the peripheral blood lymphocyte count. A receiver operating characteristic (ROC) curve was used to determine the cutoff value of NLR at initial RAI treatment in predicting prognosis. Furthermore, the prognosis was analyzed by stratification on the basis of the presence or absence of extracted independent prognostic factors.

\section{Statistical analysis}

Differences in medians between the groups were compared with nonparametric Kruskal-Wallis tests. The CSS rate was calculated using the Kaplan-Meier procedure starting from the time when distant metastasis was detected, and a logrank test was used to determine the significance. The Cox proportional hazards model was performed to determine the hazard ratio (HRs) of variables with 95\% CIs for survival rate. Multivariate analysis using the Cox proportional hazards model was conducted for parameters shown to be significant in the univariate analysis. Statistical analysis software JMP (version 12; SAS Institute Inc., Cary, NC) was used for statistical analyses and a $P$-value of $<0.05$ was considered statistically significant for all tests. All patients were verbally informed about the study at the time of treatment, which was approved by the institutional review board of Ito Hospital.

\section{Results}

\section{Patient characteristics}

Patient characteristics are shown in Table 1. Median patient age at the time of initial surgery is 41 (range: 4-77) years. The male: female ratio was $1: 2.7$, and histological type was papillary thyroid carcinoma (PTC) and follicular thyroid carcinoma (FTC) in 83 (67.5\%) and 40 (32.5\%) patients, respectively. Median age at the discovery of lung metastasis was 47 (range: 6-78) years; 67 (54.5\%) and 56 (45.5\%) patients had synchronous and metachronous lung metastasis, respectively. The median lung tumor diameter during initial RAI treatment was 7.5 (range: 1-40) $\mathrm{mm}$. The median time to detection of distant metastasis in case of metachronous detection was 90 (range: 8-329) months. The median age at the time of initial RAI treatment was 48 (range: 7-78) years, the total RAI dose (median) was $258 \mathrm{mCi}$, and the total RAI dose exceeded $600 \mathrm{mCi}$ in 10 patients. Median NLR at initial RAI treatment was 1.79 . The median follow-up period with July 2020 as the final observation date was 147 (14-534) months. The cumulative CSS rates in all patients

Table 1 Patient characteristics.

\begin{tabular}{|c|c|}
\hline Variable & $n=123$ \\
\hline \multicolumn{2}{|l|}{ Age at operation (years) } \\
\hline Median & $41(4-77)$ \\
\hline$<55$ & $84(68.3)$ \\
\hline$\geq 55$ & $39(31.7)$ \\
\hline \multicolumn{2}{|l|}{ Gender } \\
\hline Male & $33(26.8)$ \\
\hline Female & $90(73.2)$ \\
\hline \multicolumn{2}{|l|}{ Pathological type } \\
\hline Papillary & $83(67.5)$ \\
\hline Follicular & $40(32.5)$ \\
\hline \multicolumn{2}{|c|}{ Tumor size of lung metastases (mm) } \\
\hline Median & $7.5(1-40)$ \\
\hline$<10$ & 70 (56.9) \\
\hline $10-15$ & $30(24.4)$ \\
\hline$>15$ & $23(18.7)$ \\
\hline \multicolumn{2}{|c|}{ Age at metastasis detection (years) } \\
\hline Median & $47(6-78)$ \\
\hline$<55$ & $77(62.6)$ \\
\hline$\geq 55$ & $46(37.4)$ \\
\hline \multicolumn{2}{|l|}{ Timing of metastasis, $n(\%)$} \\
\hline Initial & $67(54.5)$ \\
\hline Developed & $56(45.5)$ \\
\hline \multicolumn{2}{|c|}{ Age at the start of RAI treatment (years) } \\
\hline Median & $48(7-78)$ \\
\hline$<55$ & $72(58.5)$ \\
\hline$\geq 55$ & $51(41.5)$ \\
\hline Total RAI dose (mCi) & $258.4(100-831)$ \\
\hline Number of RAI treatment & $3(1-8)$ \\
\hline NLR & $1.79(0.74-6.5)$ \\
\hline \multicolumn{2}{|c|}{$\begin{array}{l}\text { Follow-up since the diagnosis of metastasis } \\
\text { (month) }\end{array}$} \\
\hline Median & $147(14-534)$ \\
\hline
\end{tabular}

Data are expressed as median (range) or number (percentage). NLR, neutrophil-to-lymphocyte ratio; RAI, radioactive iodine. 


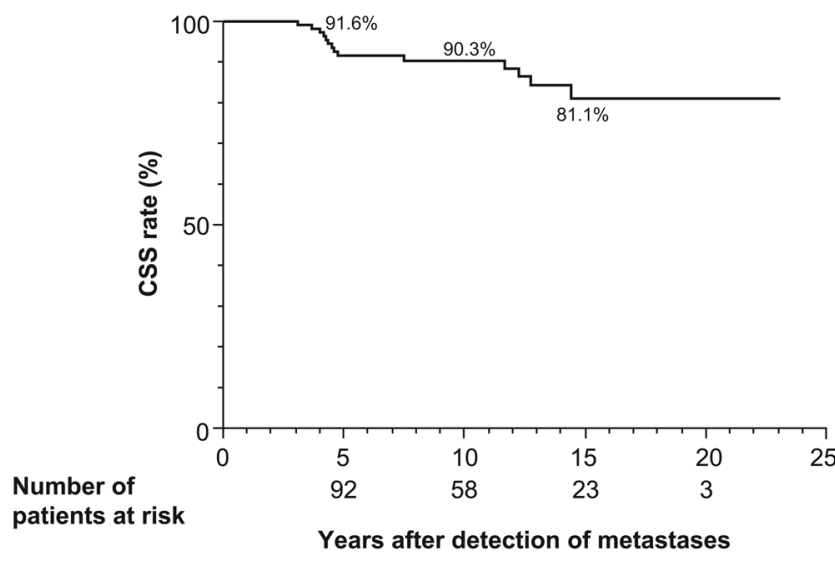

Figure 2

Cause-specific survival of patients with lung metastasis of differentiated thyroid cancer.

were as follows: 5 years, 91.6\%; 10 years, 90.3\% and 15 years, $81.1 \%$ (Fig. 2).

\section{NLR}

The optimal NLR cutoff value was calculated by drawing a ROC curve. As a result, the NLR cutoff value before the initial RAI treatment was 2.615 , sensitivity was 0.5714 , specificity was 0.8378 , and the area under the curve was 0.6966 (Fig. 3A). All patients were divided into groups with NLR of $<2.6$ or NLR of $\geq 2.6$, and the CSS rates were compared. A significant difference in survival was observed between the two groups, and the cause-specific cumulative survival in the NLR $\geq 2.6$ group was as follows: 5 years, $79.5 \%$; 10 years, $73.3 \%$ and 15 years, $55.0 \%$ $(P=0.0003)$ (Fig. 3B).

\section{Analysis of prognostic factors}

The results of univariate analysis using the Cox proportional hazards model revealed the following prognostic factors: age $\geq 55$ years at the time of operative treatment $(P<0.0001)$, follicular carcinoma $(P=0.0123)$, lung metastasis tumor $\geq 10 \mathrm{~mm}$ in diameter $(P=0.0006)$, age $\geq 55$ years $(P<0.0001)$ at the time of detection of lung metastasis, age $\geq 55$ years $(P<0.0001)$ at the time of RAI treatment, and NLR $\geq 2.6$ at the initial RAI treatment $(P=0.0003)$. In multivariate analysis, lung metastatic tumor $\geq 10 \mathrm{~mm}$ in diameter (hazard ratio (HR): 5.93; 95\% CI: $1.402-44.980 ; P=0.0129)$ and NLR $\geq 2.6$ at the initial RAI treatment (HR: 7.41; 95\% CI: 2.229-29.438; $P=0.0011)$ were used as independent prognostic factors (Table 2).

\section{Stratified analysis of prognostic factors for CSS}

The two extracted prognostic factors, that is, lung metastatic tumor $\geq 10 \mathrm{~mm}$ in diameter and NLR $\geq 2.6$ at the initial RAI treatment, were stratified using the number of corresponding factors. Prognosis was analyzed based on stratification of the group with 0 items as the low-risk group, the group with one item as the intermediate-risk group, and the group with all two items as the high-risk group. Patient characteristics based on risk stratification are shown in Table 3. Patients with higher risk were significantly more likely to have older age at surgery, follicular carcinoma, older age at distant metastases detection, larger metastatic lung tumor diameter, older age at the start of RAI treatment, and higher NLR. As depicted in Fig. 4, the 5-, 10-, and 15-year survival rates after metastasis detection in the high-risk group were 69.5, 59.7, and $19.9 \%$, respectively, which were much worse than those in the low- and intermediate-risk groups (Table 4). The prognosis was good in the low-risk and intermediaterisk groups but poor in the high-risk group.

\section{Discussion}

Distant metastasis of DTC is not uncommon during treatment, which may be either diagnosed at the time of thyroid cancer detection or during follow-up $(18,19)$. In PTC and FTC with distant metastasis, RAI treatment is the first choice unless the patient loses RAI accumulation capacity (20). Patients with distant metastases can have a long-term survival depending on the extent of radioiodine uptake in the distant metastases. The fact that iodine activity in metastases is a statistically significant favorable prognostic factor which has also been confirmed by other investigators $(21,22,23)$. Even in those patients who accumulate iodine in distant metastases, there are cases that resist treatment and continue to progress. Such radioiodine-resistant patients are candidates for TKI therapy. In this study, we hypothesized that by identifying predictable prognostic factors at the initial stage of RAI treatment in patients with DTC and RAI-avid lung metastases, we could consider the appropriate time for treatment selection. As a result, we found that NLR $\geq 2.6$ at the time of the first RAI treatment and maximum lung metastasis diameter $\geq 10 \mathrm{~mm}$ at the time of RAI treatment were poor prognostic factors. In addition, the presence of both these factors was also a poor prognostic factor.

RAI therapy forms the core treatment of DTC with distant metastasis. Durante et al. examined 441 patients

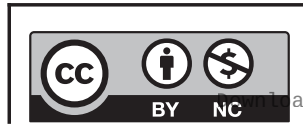

This work is licensed under a Creative Commons Attribution-NonCommercial 4.0 International License. ded from Bioscientifica.com at 04/26/2023 06:09:23AM via free access 
A
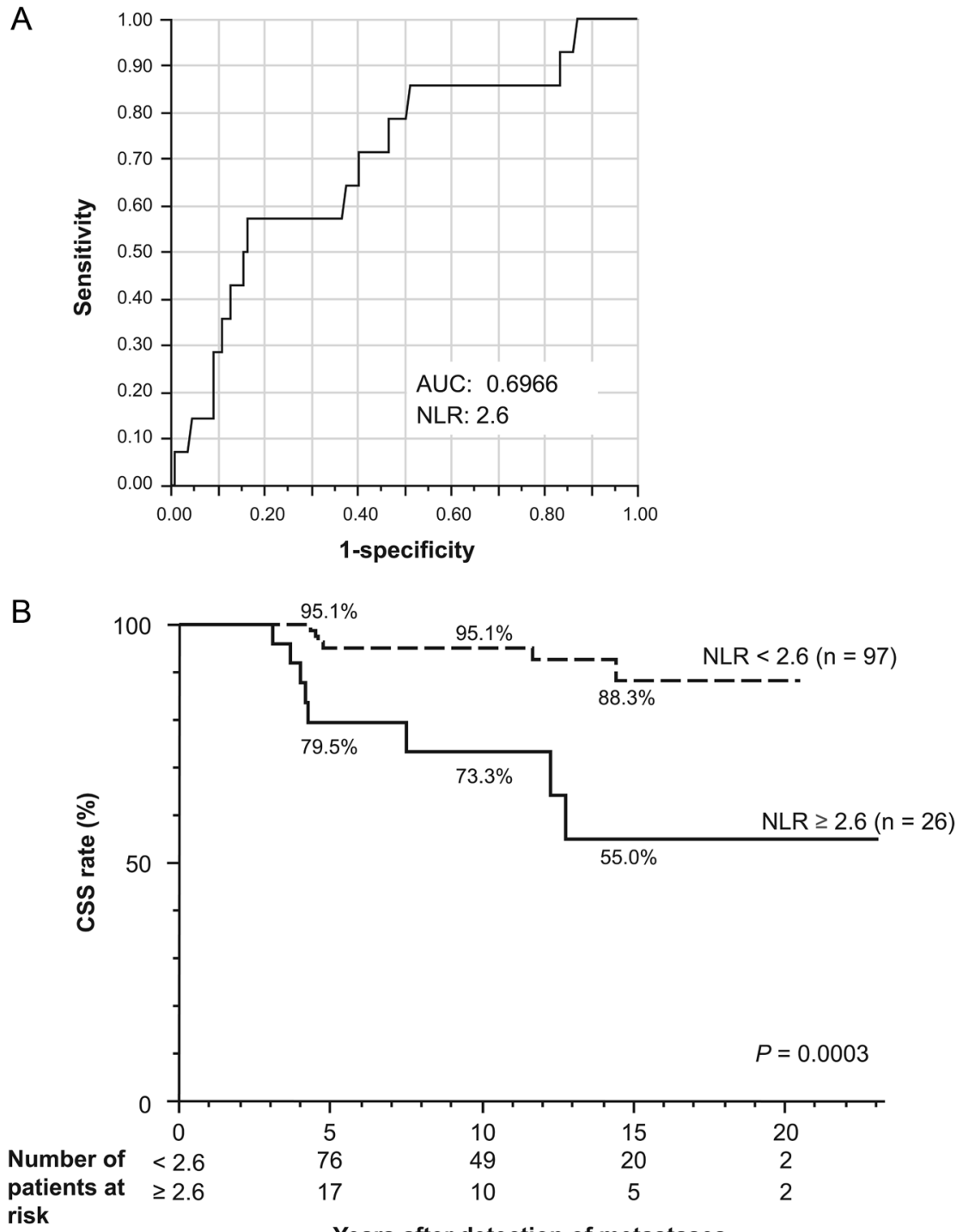

Figure 3

(A) ROC curve to determine cutoff values for NLR. On the basis of ROC curves, cutoff values with the best discriminatory power for NLR were 2.61 . (B) Survival after the discovery of lung metastases according to the NLR. with distant metastasis of DTC and reported that factors of poor prognosis include male sex, age $\geq 40$ years, poor differentiation, and no accumulation of iodine (8). Nixon et al. reported that prognosis was determined based on the presence of nonlung metastatic lesions, including bone metastasis, and the absence of RAI accumulation (5). The presence or absence of RAI accumulation, size of metastatic lung tumor, histopathological type, and the timing of appearance of metastasis have been reported to affect prognosis $(22,24,25)$. Therefore, the efficacy of treatment may depend on the ability of metastatic lesions to iodine uptake.

Song et al. reported that among patients with lung metastases from DTC, including those with RAI accumulation in lung metastases, a poorer prognosis was seen in patients with lung metastatic tumor diameter of $\geq 1 \mathrm{~cm}$, age $\geq 40$ years, and metastases in organs other than the lung (26). In this study, lung metastasis with a tumor diameter of $\geq 1 \mathrm{~cm}$ was an independent prognostic factor.

In clinical practice, as long as there is RAI accumulation in the metastatic lesion under RAI therapy, RAI is continued if the disease does not progress or treatment is successful. However, the disease may progress during the course of treatment, and in recent years, moleculartargeted drug therapeutic agents, such as TKIs, have been broadly introduced to treat distant metastases of differentiated cancers in patients with thyroid cancer showing RAI resistance $(8,24)$. When performing RAI therapy, data for determining whether there is constant resistance to treatment are indispensable, and determining the prognosis at an early stage is important. 
Table 2 Univariate and multivariate analyses to detect independent prognostic factors.

\begin{tabular}{|c|c|c|c|c|c|c|c|}
\hline \multirow[b]{2}{*}{ Variables } & \multirow[b]{2}{*}{$n$} & \multicolumn{3}{|c|}{ Survival, \% } & \multirow{2}{*}{$\begin{array}{c}\text { Univariate analysis, } \\
\text { P-value }\end{array}$} & \multicolumn{2}{|c|}{ Multivariate analysis } \\
\hline & & 5-year & 10-year & 15-year & & $\mathrm{HR}(95 \% \mathrm{Cl})$ & $P$-value \\
\hline \multicolumn{8}{|c|}{ Age at operation (years) } \\
\hline$<55$ & 84 & 100 & 100 & 89.5 & $<0.0001$ & $5.23(0.427-164.47)$ & 0.214 \\
\hline$\geq 55$ & 39 & 72.2 & 67.0 & 67.0 & & & \\
\hline \multicolumn{8}{|l|}{ Gender } \\
\hline Male & 33 & 92.8 & 86.7 & 63.5 & 0.3826 & & \\
\hline Female & 90 & 91.2 & 91.2 & 85.8 & & & \\
\hline \multicolumn{8}{|c|}{ Pathological type } \\
\hline Papillary & 83 & 95.9 & 94.1 & 86.9 & 0.0123 & $1.23(0.394-4.131)$ & 0.7206 \\
\hline Follicular & 40 & 82.8 & 82.8 & 66.3 & & & \\
\hline \multicolumn{8}{|c|}{$\begin{array}{l}\text { Tumor size of lung } \\
\text { metastases (mm) }\end{array}$} \\
\hline$<10$ & 70 & 96.7 & 96.7 & 96.7 & 0.0006 & $5.93(1.402-44.980)$ & 0.0129 \\
\hline$\geq 10$ & 53 & 85.1 & 82.1 & 60.2 & & & \\
\hline \multicolumn{8}{|c|}{$\begin{array}{l}\text { Age at metastasis } \\
\text { detection (years) }\end{array}$} \\
\hline$<55$ & 77 & 100.0 & 100.0 & 91.0 & $<0.0001$ & $1.24(0.047-32.821)$ & 0.8814 \\
\hline$\geq 55$ & 46 & 76.4 & 72.2 & 60.1 & & & \\
\hline \multicolumn{8}{|c|}{ Time of lung metastasis } \\
\hline Initial & 67 & 91.3 & 91.3 & 87.8 & 0.3831 & & \\
\hline Developed & 56 & 92.0 & 89.2 & 72.9 & & & \\
\hline \multicolumn{8}{|c|}{$\begin{array}{l}\text { Age at the start of RAI } \\
\text { treatment (years) }\end{array}$} \\
\hline$<55$ & 72 & 100 & 100 & 94.2 & $<0.0001$ & $6.98(0.294-89.107)$ & 0.1876 \\
\hline$\geq 55$ & 51 & 79.2 & 75.6 & 51.0 & & & \\
\hline \multicolumn{8}{|l|}{ NLR at first RAI } \\
\hline$<2.6$ & 97 & 95.1 & 95.1 & 88.3 & 0.0003 & $7.41(2.229-29.438)$ & 0.0011 \\
\hline$\geq 2.6$ & 26 & 79.5 & 73.3 & 55.0 & & & \\
\hline
\end{tabular}

HR, hazard ratio; NLR, neutrophil-to-lymphocyte ratio; RAl, radioactive iodine.

NLR has been reported as a prognostic factor for various carcinomas, suggesting that high NLR level and prognosis might be related (27). An increased neutrophil count promotes tumor growth and metastasis due to the fact that neutrophils play an important role in the production of ligands that induce tumor cell proliferation and infiltration and cytokines that induce angiogenesis. Moreover, lymphocytes control the host's immune

Table 3 Patient characteristics by risk stratification.

\begin{tabular}{l}
\hline Variables \\
\hline Age at operation (years) \\
Gender \\
Male \\
Female \\
Pathological type \\
Papillary \\
Follicular \\
Age at metastasis detection (years) \\
Tumor size of lung metastases (mm) \\
Timing of metastasis, $n$ (\%) \\
Synchronous \\
Metachronous \\
Age at the start of RAI treatment \\
(years) \\
Total RAl dose (mCi) \\
NLR
\end{tabular}

\begin{tabular}{c}
\hline Low $(n=58)$ \\
\hline $28(4-76)$ \\
$13(22.4)$ \\
$45(77.6)$ \\
$49(84.5)$ \\
$9(15.5)$ \\
$39(9-78)$ \\
$5(1-9)$ \\
$32(55.2)$ \\
$26(44.8)$ \\
$41(9-78)$
\end{tabular}

\begin{tabular}{c}
\hline Intermediate $(n=51)$ \\
\hline $47(11-77)$ \\
$14(27.5)$ \\
$37(72.5)$ \\
$27(52.9)$ \\
$24(47.1)$ \\
$52(11-76)$ \\
$12(4-31)$ \\
$29(56.9)$ \\
$22(43.1)$ \\
$55(11-77)$
\end{tabular}

\begin{tabular}{c}
\hline High $(n=14)$ \\
\hline $58(6-75)$ \\
$6(42.9)$ \\
$8(57.1)$ \\
$7(50.0)$ \\
$7(50.0)$ \\
$60(6-77)$ \\
$15.5(10-40)$ \\
$6(42.9)$ \\
$8(57.1)$ \\
$62(7-78)$ \\
$279.5(100-831)$ \\
$3.13(2.62-5.64)$ \\
\hline
\end{tabular}

\begin{tabular}{r}
\hline \multicolumn{1}{c}{$\boldsymbol{P}$-value } \\
\hline 0.0033 \\
0.3210 \\
\\
0.0005 \\
0.0089 \\
$<0.0001$ \\
0.6417 \\
0.0065 \\
0.1913 \\
$<0.0001$
\end{tabular}

Data are expressed as median (range) or number (percentage). NLR, neutrophil-to-lymphocyte ratio; RAI, radioactive iodine.

https://ec.bioscientifica.com https://doi.org/10.1530/EC-21-0215 (c) 2021 The authors Published by Bioscientifica Ltd
$24.7(100-655)$

$1.97(0.87-6.5)$ 


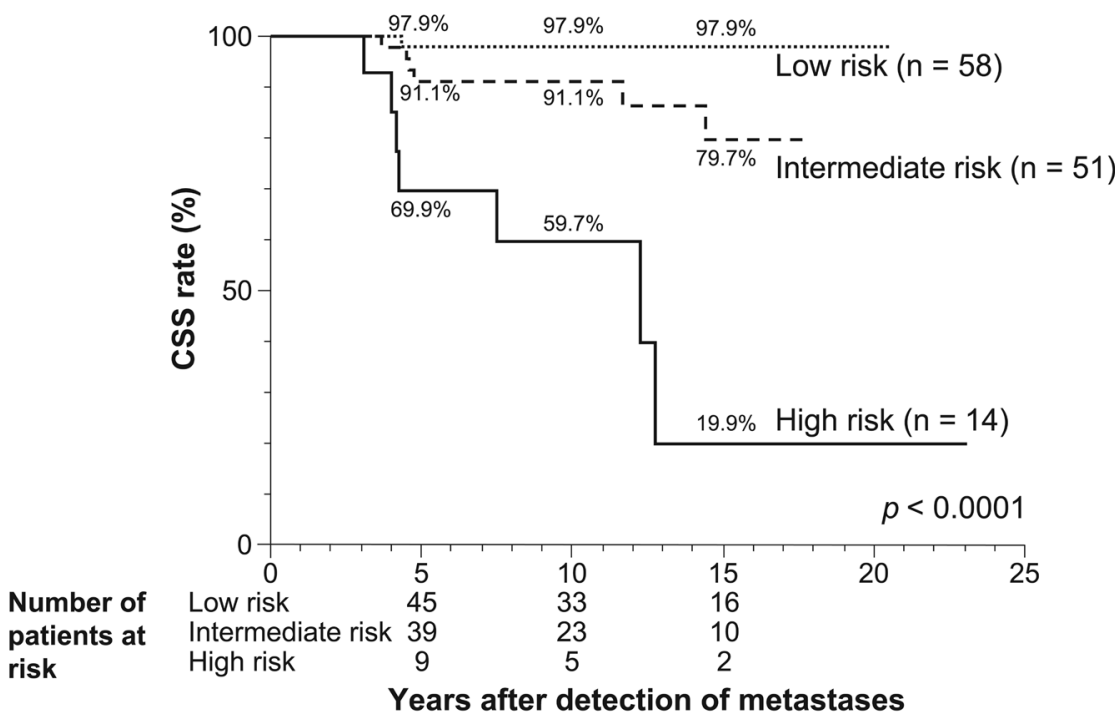

\section{Figure 4}

Survival after the discovery of lung metastases according to the risk score. Low risk, NLR $<2.6$, and metastatic lung tumor $<10 \mathrm{~mm}$ in diameter; intermediate risk, NLR $\geq 2.6$ or metastatic lung tumor $\geq 10 \mathrm{~mm}$ in diameter; high risk, NLR $\geq 2.6$ and metastatic lung tumor $\geq 10 \mathrm{~mm}$ in diameter. function, and lymphocyte depletion impairs the host's antitumor immunity, leading to worsened prognosis (28, 29). Hence, NLR is regarded to reflect the balance between the tumor-promoting environment and antitumor immune status.

To date, several reports concerning NLR, prognosis, and recurrence exist, especially regarding papillary thyroid cancer. Kim et al. reported that a high NLR is a prognosis predictor for disease-free survival (DFS) in patients with stage III or IV papillary thyroid cancer (30). Lee et al. reported that preoperative NLR for papillary thyroid cancer in patients aged $\geq 45$ years is an independent predictor of DFS (31). In a meta-analysis of 3081 patients, Feng et al. reported that pretreatment NLR may be an excellent biomarker for predicting tumor size, metastasis, and prognosis in thyroid cancer (32). In this study, NLR levels at the time of initial RAI treatment were confirmed to be a useful biomarker correlated with prognosis in patients with RAI-avid lung metastasis. It was possible to explore the prognostic indicators by stratification based on risk factors. If a patient has both a lung mass $\geq 1 \mathrm{~cm}$ and a high NLR, the prognosis is very poor.

Demir et al. examined the changes in inflammatory markers after RAI treatment in patients with DTC over time using RAI treatment, non-RAI treatment, and healthy subject groups; NLR was found to increase significantly 2 months after RAI. Although NLR subsequently and comparatively decreased, it remained high, and this change was reportedly due to systemic inflammation caused by RAI ablation to residual thyroid tissue (16). Furthermore, Kutluturk et al. observed blood-cell count variability due to thyroid hormone fluctuations in patients during RAI treatment and reported no statistical difference due to thyroid hormone fluctuations (33). In this study, the NLR measurement time of the patients was uniform immediately before RAI treatment in the environment of elevated thyroid-stimulating hormone, and considering the effects of RAI treatment was not necessary.

In general, there are no clear criteria for the cutoff value of NLR. Malnutrition and poor immunity can also increase the NLR. However, RAI treatment is not applied for patients with poor general health. Therefore, the NLR values in this study were considered to reflect the influence of tumor-related factors. When using these indicators, it is important to always re-evaluate the interpretation of the numerical values, giving due consideration to the purpose of use, the characteristics of the target population, the stage of the disease, etc.

This study has several limitations. It was a retrospective study and included patients who had undergone RAI

Table 4 Risk stratification based on risk factors.

\begin{tabular}{|c|c|c|}
\hline & $n$ & $\mathbf{H R}(95 \% \mathrm{Cl})$ \\
\hline Low risk & 58 & Ref \\
\hline Intermediate risk & 51 & $6.99(1.19-132.00)$ \\
\hline High risk & 14 & $41.72(7.34-782.83)$ \\
\hline \multicolumn{3}{|l|}{ HR, hazard ratio; ref, reference. } \\
\hline $\begin{array}{l}\text { https://ec.bioscientifica.com } \\
\text { https://doi.org/10.1530/EC-21-0215 }\end{array}$ & & $\begin{array}{l}\text { (c) } 2021 \text { The authors } \\
\text { Published by Bioscientifica Ltd }\end{array}$ \\
\hline
\end{tabular}

\begin{tabular}{|c|c|c|c|}
\hline \multirow[b]{2}{*}{ P-value } & \multicolumn{3}{|c|}{ Survival, \% } \\
\hline & 5-year & 10-year & 15-year \\
\hline & 97.9 & 97.9 & 97.9 \\
\hline 0.0292 & 91.1 & 91.1 & 79.7 \\
\hline$<0.0001$ & 69.6 & 59.7 & 19.9 \\
\hline
\end{tabular}


treatments ranging from one to eight and included those who initially showed RAI uptake but lost the uptake after repeated treatments (RAI-resistant patients). In addition, cases in which other organ metastases, such as bone metastases, appeared during the follow-up were not excluded, which might have affected the prognosis.

\section{Conclusion}

Among cases of lung metastases of differentiated thyroid carcinoma with RAI accumulation, those with high NLR at initial RAI treatment and those with lung metastasis tumor $\geq 10 \mathrm{~mm}$ in diameter may have a poor prognosis. As a result of risk stratification based on prognostic factors, the prognosis of the high-risk group was found to be extremely poor, which means that they can be considered as candidates for TKI therapy in the future.

\section{Declaration of interest}

The authors declare that there is no conflict of interest that could be perceived as prejudicing the impartiality of the research reported.

\section{Funding}

This research did not receive any specific grant from any funding agency in the public, commercial, or not-for-profit sector.

\section{Acknowledgement}

The authors thank all the stuff of Ito Hospital who contributed to this study.

\section{References}

1 Davies L \& Welch HG. Current thyroid cancer trends in the United States. JAMA Otolaryngology: Head and Neck Surgery 2014140 317-322. (https://doi.org/10.1001/jamaoto.2014.1)

2 Li R, Wang Y \& Du L. A rapidly increasing trend of thyroid cancer incidence in selected East Asian countries: joinpoint regression and age-period-cohort analyses. Gland Surgery 2020 9 968-984. (https:// doi.org/10.21037/gs-20-97)

3 Huang IC, Chou FF, Liu RT, Tung SC, Chen JF, Kuo MC, Hsieh CJ $\&$ Wang PW. Long-term outcomes of distant metastasis from differentiated thyroid carcinoma. Clinical Endocrinology 201276 439-447. (https://doi.org/10.1111/j.1365-2265.2011.04231.x)

4 Mihailovic J, Stefanovic L, Malesevic M \& Markoski B. The importance of age over radioiodine avidity as a prognostic factor in differentiated thyroid carcinoma with distant metastases. Thyroid 200919 227-232. (https://doi.org/10.1089/thy.2008.0186)

5 Nixon IJ, Whitcher MM, Palmer FL, Tuttle RM, Shaha AR, Shah JP, Patel SG \& Ganly I. The impact of distant metastases at presentation on prognosis in patients with differentiated carcinoma of the thyroid gland. Thyroid 201222 884-889. (https://doi.org/10.1089/thy.2011.0535)

6 Lee J \& Soh EY. Differentiated thyroid carcinoma presenting with distant metastasis at initial diagnosis clinical outcomes and prognostic factors. Annals of Surgery 2010251 114-119. (https://doi.org/10.1097/ SLA.0b013e3181b7faf6)

7 Haugen BR, Alexander EK, Bible KC, Doherty GM, Mandel SJ, Nikiforov YE, Pacini F, Randolph GW, Sawka AM, Schlumberger M, et al. 2015 American Thyroid Association management guidelines for adult patients with thyroid nodules and differentiated thyroid cancer: the American Thyroid Association Guidelines Task Force on thyroid nodules and differentiated thyroid cancer. Thyroid 201626 1-133. (https://doi.org/10.1089/thy.2015.0020)

8 Durante C, Haddy N, Baudin E, Leboulleux S, Hartl D, Travagli JP, Caillou B, Ricard M, Lumbroso JD, De Vathaire F, et al. Long-term outcome of 444 patients with distant metastases from papillary and follicular thyroid carcinoma: benefits and limits of radioiodine therapy. Journal of Clinical Endocrinology and Metabolism 200691 2892-2899. (https://doi.org/10.1210/jc.2005-2838)

9 Schlumberger M, Brose M, Elisei R, Leboulleux S, Luster M, Pitoia F \& Pacini F. Definition and management of radioactive iodine-refractory differentiated thyroid cancer. Lancet: Diabetes and Endocrinology 20142 356-358. (https://doi.org/10.1016/S2213-8587(13)70215-8)

10 Schlumberger M, Tahara M, Wirth LJ, Robinson B, Brose MS, Elisei R, Habra MA, Newbold K, Shah MH, Hoff AO, et al. Lenvatinib versus placebo in radioiodine-refractory thyroid cancer. New England Journal of Medicine 2015372 621-630. (https://doi.org/10.1056/ NEJMoa1406470)

11 Brose MS, Nutting CM, Jarzab B, Elisei R, Siena S, Bastholt L, de la Fouchardiere C, Pacini F, Paschke R, Shong YK, et al. Sorafenib in radioactive iodine-refractory, locally advanced or metastatic differentiated thyroid cancer: a randomised, double-blind, phase 3 trial. Lancet 2014384 319-328. (https://doi.org/10.1016/S01406736(14)60421-9)

12 Azab B, Bhatt VR, Phookan J, Murukutla S, Kohn N, Terjanian T \& Widmann WD. Usefulness of the neutrophil-to-lymphocyte ratio in predicting short- and long-term mortality in breast cancer patients. Annals of Surgical Oncology 201219 217-224. (https://doi.org/10.1245/ s10434-011-1814-0)

13 Cho H, Hur HW, Kim SW, Kim SH, Kim JH, Kim YT \& Lee K. Pretreatment neutrophil to lymphocyte ratio is elevated in epithelial ovarian cancer and predicts survival after treatment. Cancer Immunology, Immunotherapy 200958 15-23. (https://doi.org/10.1007/ s00262-008-0516-3)

14 Moore MM, Chua W, Charles KA \& Clarke SJ. Inflammation and cancer: causes and consequences. Clinical Pharmacology and Therapeutics 201087 504-508. (https://doi.org/10.1038/clpt.2009.254)

15 Liu CL, Lee JJ, Liu TP, Chang YC, Hsu YC \& Cheng SP. Blood neutrophil-to-lymphocyte ratio correlates with tumor size in patients with differentiated thyroid cancer. Journal of Surgical Oncology 2013 107 493-497. (https://doi.org/10.1002/jso.23270)

16 Demir Y, Üçler R, Sürücü E, Turan M, Balli Z \& Şengöz T. Temporary changes in neutrophil-to-lymphocyte, platelet-to-lymphocyte ratios, and mean platelet volume reflecting the inflammatory process after radioiodine therapy. Nuclear Medicine Communications 201637 393-398. (https://doi.org/10.1097/MNM.0000000000000452)

17 Monzen S, Mariya Y, Wojcik A, Kawamura C, Nakamura A, Chiba M, Hosoda M \& Takai Y. Predictive factors of cytotoxic damage in radioactive iodine treatment of differentiated thyroid cancer patients. Molecular and Clinical Oncology 20153 692-698. (https://doi. org/10.3892/mco.2015.499)

18 de Melo TG, Zantut-Wittmann DE, Ficher E \& da Assumpção LV. Factors related to mortality in patients with papillary and follicular thyroid cancer in long-term follow-up. Journal of Endocrinological Investigation 201437 1195-1200. (https://doi.org/10.1007/s40618-0140131-4)

19 Nixon IJ, Ganly I, Palmer FL, Whitcher MM, Patel SG, Tuttle RM, Shaha AR \& Shah JP. Disease-related death in patients who were considered free of macroscopic disease after initial treatment of well- https://ec.bioscientifica.com https://doi.org/10.1530/EC-21-0215 (c) 2021 The authors Published by Bioscientifica Ltd

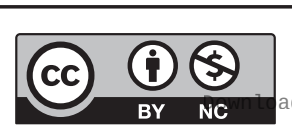

This work is licensed under a Creative Commons Attribution-NonCommercial 4.0 International License. ded from Bioscientifica.com at 04/26/2023 06:09:23AM 
differentiated thyroid carcinoma. Thyroid 201121 501-504. (https:// doi.org/10.1089/thy.2010.0451)

20 Phay JE \& Ringel MD. Metastatic mechanisms in follicular cell-derived thyroid cancer. Endocrine-Related Cancer 201320 R307-R319. (https:// doi.org/10.1530/ERC-13-0187)

21 Sampson E, Brierley JD, Le LW, Rotstein L \& Tsang RW. Clinical management and outcome of papillary and follicular (differentiated) thyroid cancer presenting with distant metastasis at diagnosis. Cancer 2007110 1451-1456. (https://doi.org/10.1002/cncr.22956)

22 Pelizzo MR, Boschin IM, Toniato A, Piotto A, Pagetta C, Gross MD, Al-Nahhas A \& Rubello D. Papillary thyroid carcinoma: 35-year outcome and prognostic factors in 1858 patients. Clinical Nuclear Medicine 200732 440-444. (https://doi.org/10.1097/ RLU.0b013e31805375ca)

23 Sisson JC, Giordano TJ, Jamadar DA, Kazerooni EA, Shapiro B, Gross MD, Zempel SA \& Spaulding SA. 131-I treatment of micronodular pulmonary metastases from papillary thyroid carcinoma. Cancer 199678 2184-2192. (https://doi.org/10.1002/ (sici) 1097-0142(19961115)78:10<2184::aid-cncr21>3.0.co;2-u)

24 Sohn SY, Kim HI, Kim YN, Kim TH, Kim SW \& Chung JH. Prognostic indicators of outcomes in patients with lung metastases from differentiated thyroid carcinoma during long-term follow-up. Clinical Endocrinology 201888 318-326. (https://doi.org/10.1111/cen.13489)

25 Cho SW, Choi HS, Yeom GJ, Lim JA, Moon JH, Park DJ, Chung JK, Cho BY, Yi KH \& Park YJ. Long-term prognosis of differentiated thyroid cancer with lung metastasis in Korea and its prognostic factors. Thyroid 201424 277-286. (https://doi.org/10.1089/thy.2012.0654)

26 Song HJ, Qiu ZL, Shen CT, Wei WJ \& Luo QY. Pulmonary metastases in differentiated thyroid cancer: efficacy of radioiodine therapy and prognostic factors. European Journal of Endocrinology 2015173 399-408. (https://doi.org/10.1530/EJE-15-0296)
27 Templeton AJ, McNamara MG, Šeruga B, Vera-Badillo FE, Aneja P, Ocaña A, Leibowitz-Amit R, Sonpavde G, Knox JJ, Tran B, et al. Prognostic role of neutrophil-to-lymphocyte ratio in solid tumors: a systematic review and meta-analysis. Journal of the National Cancer Institute 2014106 dju124. (https://doi.org/10.1093/jnci/dju124)

28 Liao WT, Ye YP, Deng YJ, Bian XW \& Ding YQ. Metastatic cancer stem cells: from the concept to therapeutics. American Journal of Stem Cells 20143 46-62.

29 Lin EY \& Pollard JW. Role of infiltrated leucocytes in tumour growth and spread. British Journal of Cancer 200490 2053-2058. (https://doi. org/10.1038/sj.bjc.6601705)

30 Kim JY, Park T, Jeong SH, Jeong CY, Ju YT, Lee YJ, Hong SC, Ha WS, Choi SK \& Jung EJ. Prognostic importance of baseline neutrophil to lymphocyte ratio in patients with advanced papillary thyroid carcinomas. Endocrine 201446 526-531. (https://doi.org/10.1007/ s12020-013-0089-6)

31 Lee KH, Seok EY, Kim EY, Yun JS, Park YL \& Park CH. Different prognostic values of individual hematologic parameters in papillary thyroid cancer due to age-related changes in immunity. Annals of Surgical Treatment and Research 201996 70-77. (https://doi.org/10.4174/ astr.2019.96.2.70)

32 Feng J, Wang Y, Shan G \& Gao L. Clinical and prognostic value of neutrophil-lymphocyte ratio for patients with thyroid cancer: a meta-analysis. Medicine 202099 e19686. (https://doi.org/10.1097/ MD.0000000000019686)

33 Kutluturk F, Gul SS, Sahin S \& Tasliyurt T. Comparison of mean platelet volume, platelet count, neutrophil/lymphocyte ratio and platelet/ lymphocyte ratio in the euthyroid, overt hypothyroid and subclinical hyperthyroid phases of papillary thyroid carcinoma. Endocrine, Metabolic and Immune Disorders Drug Targets 201919 859-865. (https:// doi.org/10.2174/1871530319666190206125545)

Received in final form 16 June 2021

Accepted 5 July 2021

Accepted Manuscript published online 5 July 2021
This work is licensed under a Creative Commons Attribution-NonCommercial 4.0 International License. ded from Bioscientifica.com at 04/26/2023 06:09:23AM 